\title{
Sistema de Informação para monitoramento de qualidade da água e apoio ao enquadramento de corpos hídricos
}

\author{
Reginaldo Rubens da Silva ${ }^{1}$, Angelo Augusto Frozza ${ }^{1}$, Antonio Carlos Beaumord ${ }^{2}$ \\ ${ }^{1}$ Instituto Federal Catarinense (IFC) - Câmpus Camboriú \\ Rua Joaquim Garcia, S/N - 88.340-960 - Camboriú - SC \\ ${ }^{2}$ Universidade do Vale do Itajaí (UNIVALI) \\ Itajaí, SC \\ \{reginaldo, frozza\}@ifc-camboriu.edu.br, beaumord@univali.br
}

\begin{abstract}
Conflicts caused by the multiple uses water resources have attracted an increasing need to adopt procedures for managing these resources. The Politica Nacional de Recursos Hidricos (PNRH) provides tools for water resources management, including guidelines on water bodies in use classes, according to their predominant uses. The implementation of this tool requires knowledge of water quality conditions in order to determine whether the water body meets the quality requirements associated with the intended use. Thus, this paper presents an information system for the monitoring of water quality and to support the framed of bodies of water.
\end{abstract}

Resumo. Os conflitos gerados pelos múltiplos usos que se faz dos recursos hídricos (RH) têm suscitado uma necessidade cada vez maior da adoção de processos de gestão destes recursos. A Política Nacional de Recursos Hídricos (PNRH) estabelece instrumentos para a gestão de RH, entre eles o enquadramento dos corpos hídricos em classes de uso, de acordo com seus usos preponderantes. A implementação deste instrumento requer o conhecimento das condições de qualidade da água, de modo a se determinar se o corpo hídrico satisfaz os requisitos de qualidade associados com o uso que se pretende fazer dele. Assim, o presente trabalho apresenta um sistema de informação (SI) para o monitoramento da qualidade da água e para o apoio ao enquadramento de corpos hídricos.

\section{Introdução}

A preocupação com a conservação dos recursos hídricos do planeta é, atualmente, tema preponderante nas mais diversas esferas da sociedade. Os conflitos gerados pelos múltiplos usos que se faz dos recursos hídricos têm gerado uma necessidade cada vez maior da adoção de processos de gestão destes recursos, de modo a possibilitar o seu uso compartilhado, bem como assegurar a sua disponibilidade, tanto para a geração atual, quanto para as gerações futuras. Frente a esta necessidade, legislações específicas têm sido formuladas, com destaque para a Lei no .9 .433 de 1997, que institui a Política Nacional de Recursos Hídricos (PNRH), e as diretrizes para a gestão destes recursos nas diferentes esferas do poder público.

Reunindo os mais modernos princípios e instrumentos de gestão de águas, muitos deles já adotados em países desenvolvidos, a PNRH traz algumas orientações gerais para a administração dos recursos hídricos: a integração da gestão dos recursos 
hídricos com a gestão do meio ambiente; a coordenação do planejamento de recursos hídricos com os setores usuários e com o planejamento nos níveis nacional, estadual e municipal; a coordenação da gestão de recursos hídricos com o uso da terra; e a integração da gestão de bacias hidrográficas com a gestão dos sistemas costeiro e estuários. Borsoi e Torres (1997), considerando os princípios que a PNRH estabelece, destacam que (i) ao tomar os limites da bacia como o perímetro da área a ser planejada, torna-se mais simples a realização do balanço hídrico; (ii) a adoção do princípio dos usos múltiplos termina com o tradicional comando do setor elétrico sobre o processo de gestão da água e iguala todos os usuários em termos de acesso; (iii) o reconhecimento do valor econômico da água é o indutor ao uso racional desse recurso natural, servindo de base para a instituição da cobrança pela utilização dos recursos hídricos; (iv) a determinação da gestão descentralizada impõe aos governos regionais e locais a responsabilidade pela tomada de decisão e tem como objetivo incluir os usuários e a sociedade organizada, em geral, no processo decisório.

Dentre os instrumentos estabelecidos pela PNRH para a gestão dos recursos hídricos, está o enquadramento de corpos de água em classes, segundo qualidade e uso preponderante. Em termos práticos, a implementação deste instrumento requer $o$ conhecimento das condições de qualidade da água, de modo a se determinar se o corpo hídrico satisfaz os requisitos de qualidade associados com o uso que se pretende dele fazer. É com base no conhecimento das condições de qualidade do corpo de água que são determinadas as medidas de controle de poluição a serem adotadas que, eventualmente, podem ser avaliadas por meio dos programas de monitoramento da qualidade da água, outro instrumento prevista na PNRH. Tanto o enquadramento, quanto o monitoramento são essenciais para o exercício da outorga e cobrança pelo uso de recursos hídricos, que consideram aspectos quantitativos e qualitativos em sua definição.

Conforme destaca Porto (2000), os corpos d'água devem ser amplamente monitorados tanto na dimensão espacial, quanto na temporal, de modo que possam fornecer, de forma eficiente, informações adicionais ao Sistema de Informações de Recursos Hídricos. Contudo, a realização de programas de monitoramento continuados tem como consequência a produção de um grande volume de dados.

Considerando-se que estes dados devem ser armazenados de forma organizada, em formato padronizado, de fácil acesso e de preferência, de um modo que permita a sua rápida recuperação, e que até mesmo sejam integrados a outros sistemas para processamento e análise, é importante prever meios para que estes requisitos sejam atendidos. Neste caso, um Sistema de Informação dispõe de todas estas características, pois, conforme Laudon e Laudon (1999), os Sistemas de Informação são ferramentas que permitem a coleta, armazenamento, tratamento, recuperação e distribuição da informação, permitindo a produção de informações que podem apoiar processos de planejamento e tomada de decisões, comuns nas atividades de gestão de recursos hídricos.

Sob a ótica desta necessidade, o presente artigo apresenta um Sistema de Informação para o monitoramento da qualidade da água e para o apoio ao enquadramento de corpos hídricos. Este SI foi construído exclusivamente com o uso de ferramentas open source e concepção baseada em sistemas Web. 


\section{Política Nacional de Recursos Hídricos - PNRH}

Tucci et. al. (2000) destacam como marcos legais da gestão de recursos hídricos,além do Código de Águas, a Constituição Federal de 1988 e a Lei no. 9.433 de 08 de janeiro de 1997, que instituiu a Política Nacional de Recursos Hídricos.

Segundo Borsoi e Torres (1997), esta lei reúne os mais modernos princípios e instrumentos de gestão de águas, muitos dos quais já são adotados em países desenvolvidos. Isto contribui para a implantação, no Brasil, de medidas realmente eficientes e eficazes de planejamento e gerenciamento.

Ainda de acordo com Borsoi e Torres (1997), com o advento da Lei dos Recursos Hídricos, o Brasil alcança as condições básicas para entrar em uma nova fase de gerenciamento dos seus recursos hídricos, na qual as comunidades envolvidas, o governo e todos os usuários decidem pelo melhor uso da água e quais os investimentos necessários, organizados em torno de suas bacias. Isto porque, com a criação dos Comitês de Bacia Hidrográfica, a Política Nacional de Recursos Hídricos permite a gestão equitativa e participativa, já que os próprios usuários são corresponsáveis pela definição da política de gestão da bacia e dos possíveis programas a serem implementados.

A PNRH representa um marco em termos de gestão de recursos hídricos, pois além de estabelecer claramente o que vem a ser o gerenciamento destes recursos, propõe uma série de instrumentos que visam garantir a eficiência do processo de gerenciamento. A lei estabelece como instrumentos da PNRH:

- os Planos de Recursos Hídricos;

- o enquadramento dos corpos de água em classes, segundo os usos preponderantes da água;

- a outorga dos direitos de uso de recursos hídricos;

- a cobrança pelo uso de recursos hídricos;

- a compensação a municípios;

- o Sistema de Informações sobre Recursos Hídricos.

A Lei $n^{\circ} .9 .433 / 97$ determina ainda que o poder público tem por obrigação assegurar:

- a necessária disponibilidade de água, em padrões de qualidade adequados aos respectivos usos, para as gerações presentes e futuras;

- a utilização racional e integrada dos recursos hídricos, incluindo transporte aquaviário, com vistas ao desenvolvimento sustentável

- a prevenção e a defesa contra eventos hidrológicos críticos, tanto de origem natural, quanto decorrentes do uso inadequado dos recursos naturais.

Para o presente trabalho, destaca-se dentre os instrumentos estabelecidos pela Lei ${ }^{\circ}$. 9.433/97, o enquadramento dos corpos hídricos em classes, tendo em vista que, para o correto enquadramento dos corpos hídricos, bem como para a verificação da manutenção destes dentro dos padrões de qualidade determinados pela legislação, é necessária a realização de programas de monitoramento da qualidade da água. Através do Sistema de Informação proposto neste trabalho é possível realizar análises dos dados coletados segundo diversos critérios e, também, realizar a validação do enquadramento dos corpos hídricos nas classes de uso levando em conta os dados de qualidade de água coletados e armazenados no sistema. 
De acordo com IGAM (2007), o enquadramento dos corpos de água fornece subsídios aos outros instrumentos da gestão de recursos hídricos, tais como a outorga e a cobrança pelo uso da água, de maneira que, quando implementados, tornam-se complementares, proporcionando às entidades gestoras destes recursos mecanismos para assegurar a disponibilidade quantitativa e qualitativa das águas. Desta forma, o enquadramento dos corpos d'água deve ser visto não somente como uma simples classificação, mas sim como um instrumento de planejamento ambiental, pois o enquadramento dos corpos d'água deve estar baseado não necessariamente no seu estado atual, mas nos níveis de qualidade que deveriam possuir ou ser mantidos para atender às necessidades estabelecidas pela comunidade (ANA, 2004).

Silva (2007) realizou um levantamento dos SI sobre recursos hídricos existentes no Brasil, com o intuito de observar as principais características destes, suas funcionalidades, as tecnologias empregadas e o enfoque operacional dado.

Analisando as informações de Silva (2007), é possível afirmar que, em âmbito nacional, o uso de ferramentas de software livre para o desenvolvimento de sistemas de informação para apoio à gestão de recursos hídricos é bastante limitado. Muitos dos sistemas existentes são desenvolvidos com o uso de ferramentas proprietárias, exigindo um alto investimento na aquisição de licenças de software. Conforme SPERB et al. (2004), a iniciativa do Governo Federal para estabelecer o uso de software livre nas organizações governamentais, juntamente com a Política Nacional de Recursos Hídricos, podem ser considerados bons motivos para o emprego deste tipo de tecnologia no desenvolvimento de SI para a gestão de recursos hídricos. Porém, outros argumentos configuram um cenário de desconhecimento ou descrença na viabilidade do emprego de software livre, em nível de SI. A limitada disponibilidade de exemplos que demonstrem os benefícios oferecidos pela adoção de plataformas abertas, bem como o pequeno número de profissionais capacitados para desenvolver e dar manutenção a SI utilizando ferramentas de software livre, são exemplos destes argumentos.

Os sistemas estudados por Silva (2007) também demonstram que o foco principal, quando se trata do desenvolvimento de sistemas de informação sobre recursos hídricos, está no uso de tecnologias de geoprocessamento. Estas ferramentas dispõem de uma forte capacidade de análise de dados, porém, sua capacidade de distribuição das informações pode ser considerada bastante fraca. Isto configura uma potencial oportunidade para o emprego da tecnologia de WebGIS que, por sua vez, tem como ponto forte a distribuição das informação, sendo que o acesso aos dados pode ser feito a partir de qualquer lugar, desde que se disponha de uma conexão com a Internet.

Com relação ao suporte ao monitoramento da qualidade da água, os sistemas analisados indicam que as soluções geralmente são construídas para aplicação em casos específicos, tornando-as praticamente soluções fechadas. As bases de dados são modeladas para comportar dados de um conjunto específico e limitado de parâmetros de qualidade de água, por exemplo. Isto dificulta o emprego destes sistemas em outros programas de monitoramento que não utilizem exatamente os mesmos parâmetros de qualidade.

Como exemplo, o Sistema Informações de Recursos Hídricos para a Bacia do Paraíba do Sul foi desenvolvido para manipular 36 parâmetros de qualidade de água (COPPETEC, 2002). No caso da adoção deste sistema para uso em outra bacia ou por outra entidade que realize o monitoramento da qualidade da água, mas que trabalhe com parâmetros de qualidade diferentes dos utilizados para a bacia do Paraíba do Sul, é 
necessário um trabalho de adaptação do sistema ou, então, uma adaptação do programa de monitoramento, passando a trabalhar somente com os parâmetros contemplados na base de dados que foi modelada para o sistema citado.

\section{SI para monitoramento de água e enquadramento de corpos hídricos}

A descrição do sistema foi realizada com base nos conceitos abordados em Silva (2007), com destaque para o resultado do levantamento dos sistemas de informação sobre recursos hídricos. As características identificadas para esses sistemas durante o levantamento foram analisadas juntamente aos especialistas em monitoramento de qualidade da água do Laboratório de Estudos de Impactos Ambientais da Universidade do Vale do Itajaí - UNIVALI e, também, junto aos especialistas em desenvolvimento de SI e Sistemas de Apoio à Decisão (SAD) do Laboratório de Computação Aplicada da UNIVALI, com o intuito de identificar quais das características seriam desejáveis para o sistema de informação proposto.

Também se buscou identificar características que, mesmo ausentes nos sistemas estudados, seriam consideradas desejáveis. Dentre estas características, se destacam: (i) a possibilidade do emprego do SI em diferentes programas de monitoramento, considerando que programas diferentes podem trabalhar com conjuntos de dados diferentes ou, até mesmo, trabalhar com o mesmo conjunto de dados, mas utilizando diferentes limites para os valores destes dados; (ii) a possibilidade da utilização da rotina de apoio ao enquadramento para confrontar os dados de qualidade coletados e armazenados, com diferentes classes de enquadramento, estabelecidas por diferentes dispositivos reguladores.

Considerando que as principais tarefas do SI são o monitoramento de qualidade da água e o apoio ao enquadramento de recursos hídricos, a definição das funcionalidades partiu das rotinas de manutenção dos dados necessários para a execução destas tarefas.

O módulo de cadastros do sistema dispõe de funcionalidades para a manutenção de dados de: Programas de monitoramento; Estações de coleta de dados de qualidade; Parâmetros de qualidade de água monitorados; Campanhas de coleta de dados de qualidade; Leituras dos parâmetros de qualidade (realizadas para cada estação em cada uma das campanhas de coleta); Membros do programa de monitoramento, com a informação dos respectivos cargos ocupados na equipe; Municípios monitorados (cobertos pelo programa de monitoramento); Classes de enquadramento para utilização posterior da rotina de validação do enquadramento.

Estas rotinas básicas de cadastros implicam na necessidade de algumas rotinas para cadastro dos seguintes dados: Categorias de parâmetros de qualidade; Parâmetros de qualidade; Métodos de análise empregados; Tipos de programas de monitoramento; Municípios; Rios; Pessoas; Instituições.

Além das rotinas de cadastros (manutenção dos dados), foram definidas rotinas para a análise dos dados de qualidade da água, como a geração de relatórios, construção de quadros resumo dos dados armazenados para um determinado programa e geração de gráficos, além da rotina específica para a validação do enquadramento, permitindo confrontar os dados de qualidade armazenados com as classes de enquadramento cadastradas para o programa de monitoramento, apoiando, assim, a tarefa de implementação do instrumento de enquadramento dos corpos hídricos. 
Outras funcionalidades básicas inerentes a um SI também foram definidas, com destaque às funcionalidades para a importação de dados de qualidade e dados de vazão, considerando que estes dados muitas vezes já são monitorados e colecionados em planilhas eletrônicas ou outros sistemas de arquivos, mesmo antes da adoção de um sistema de informação.

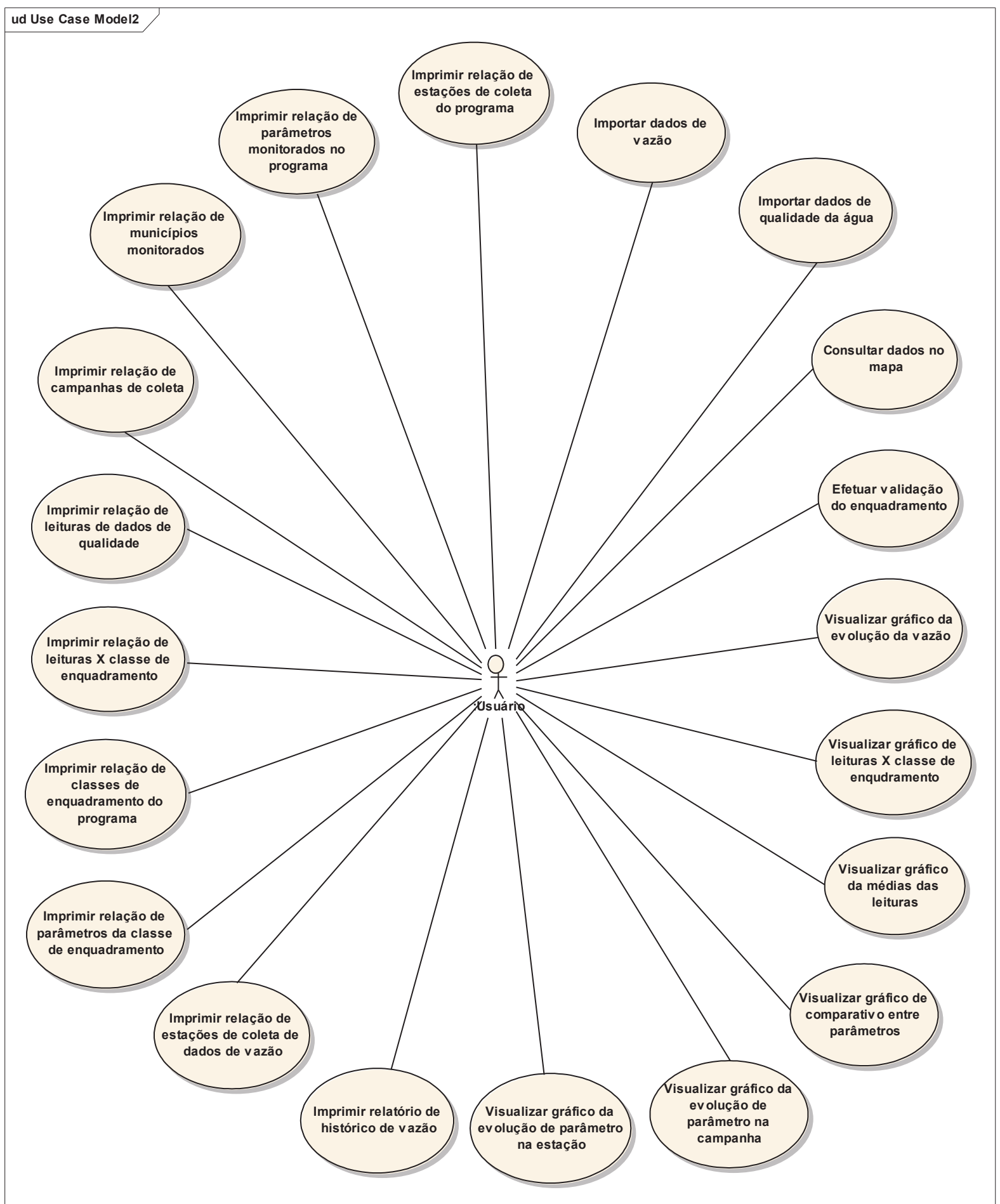

Figura 1. Principais funcionalidades do SI 
Dado que a localização geográfica das estações de coleta constitui uma informação importante e que, portanto, é contemplada pela modelagem da base de dados, foi definida uma funcionalidade para visualização de dados geoespaciais. Esta funcionalidade ilustra o potencial do emprego da tecnologia de WebGIS na construção de SI para recursos hídricos.

A Figura 1 apresenta somente a parte do diagrama de casos de uso correspondente às funcionalidades mais complexas do SI. Mais detalhes sobre a modelagem encontram-se em Silva (2007).

\section{Apresentação do sistema}

Dentre as funcionalidades implementadas para suporte ao monitoramento da qualidade da água, estão opções para a visualização de quadros resumo dos dados de qualidade cadastrados para uma determinada campanha de coleta ou então, para uma determinada estação. Estes quadros resumo permitem a visualização em forma de tabela, dos dados que também podem ser analisados através de gráficos. Na Figura 2 é apresentada a tela do SI com a visualização de um quadro resumo para uma campanha de coleta.

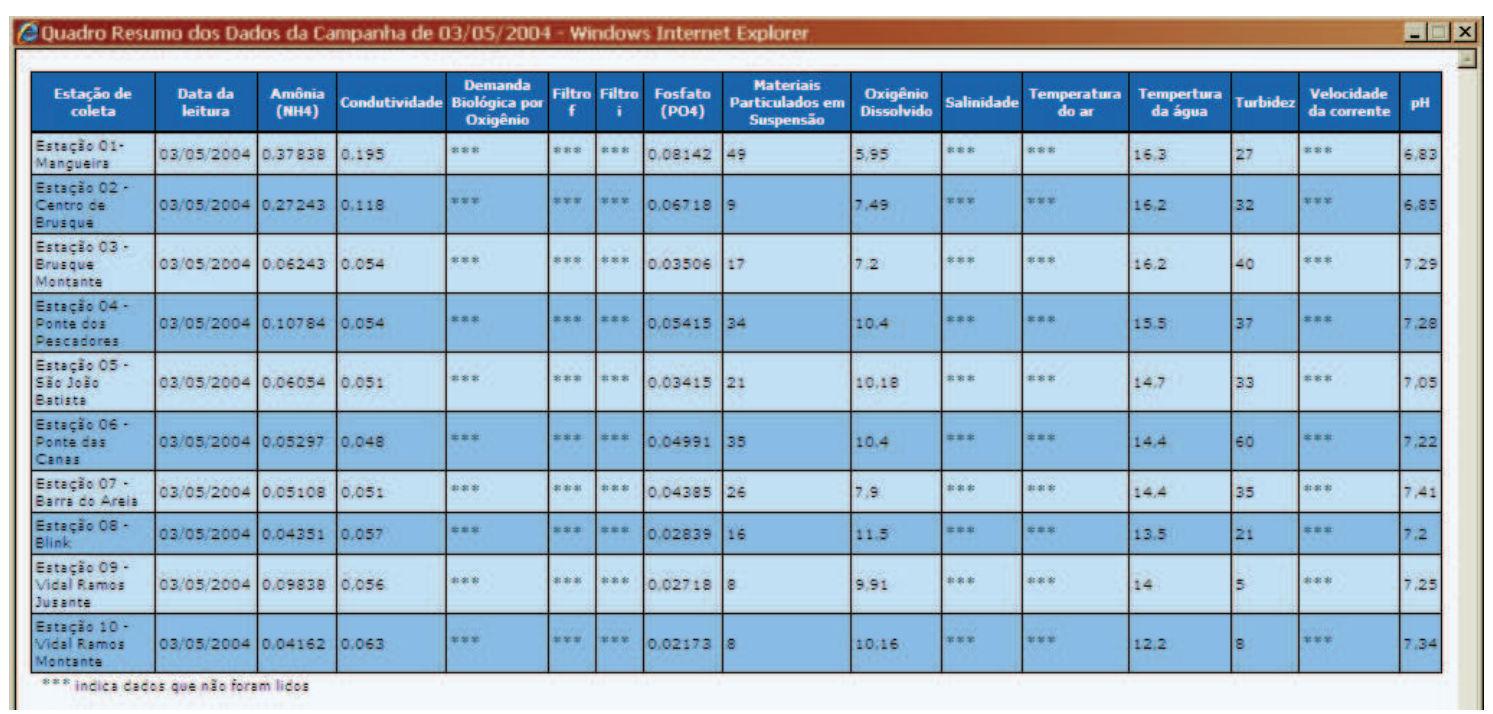

Figura 2 - Quadro resumo dos dados de qualidade de uma campanha de coleta

O quadro na Figura 2 apresenta os valores coletados para os diversos parâmetros físico-químicos monitorados pelo Programa de Monitoramento em cada uma das estações cadastradas para o programa.

Variados modelos de gráficos constituem as demais funcionalidades para análise dos dados de qualidade resultantes dos programas de monitoramento, juntamente com alguns relatórios. Tais gráficos podem apresentar a evolução de parâmetros de acordo com as leituras realizadas em uma determinada campanha de coleta ou, ainda, para uma determinada estação. A Figura 3 apresenta um exemplo de gráfico da evolução de parâmetro na campanha de coleta, que permite verificar quais as variações apresentadas por um determinado parâmetro durante uma campanha.

O módulo de apoio ao enquadramento de corpos d'água conta com funcionalidades para o cadastramento das classes de enquadramento que se deseja utilizar para cada programa de monitoramento e seus respectivos padrões de qualidade (limites máximos ou mínimos para cada um dos parâmetros monitorados). Uma vez 
cadastradas as classes de enquadramento e definidos os padrões de qualidade para cada uma delas, o SI oferece uma opção para a validação do enquadramento, cujo objetivo é comparar os dados de qualidade cadastrados no sistema com os limites estabelecidos para uma determinada classe. Nesta opção, o usuário indica se deseja considerar para a validação do enquadramento as médias de todas as campanhas de coleta realizadas no programa, as médias das campanhas realizadas durante um período de tempo específico ou, ainda, os dados lidos em uma única campanha de coleta. É possível, também, optar por validar todas as estações de coleta do programa ou somente uma estação em especial. Por fim, o usuário seleciona a classe para a qual deseja validar os dados de qualidade.

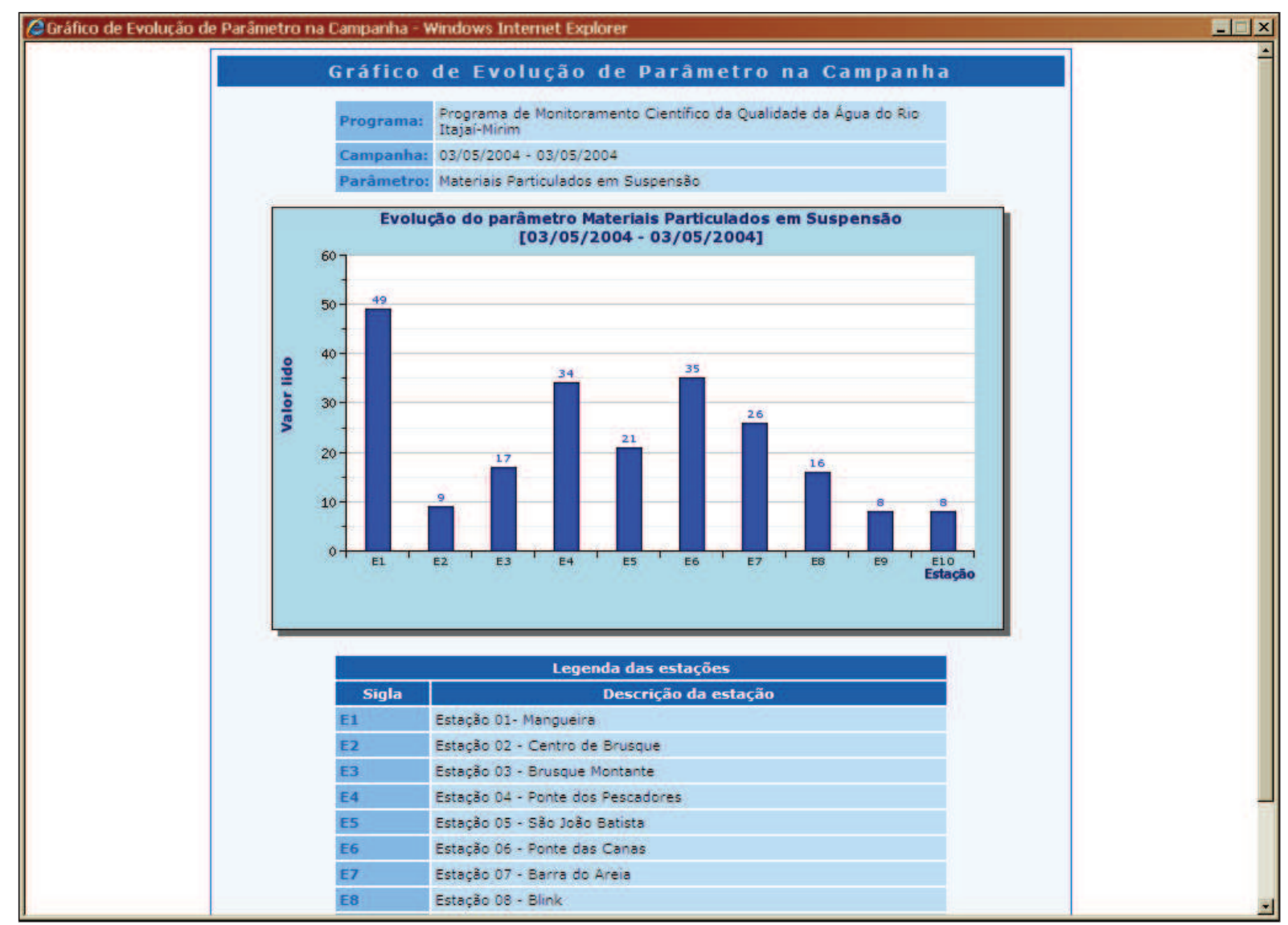

Figura 3 - Gráfico de evolução de parâmetro na campanha de coleta

Depois de configurados os dados, o SI realiza a validação e apresenta como resultado para cada estação a relação dos valores lidos para os parâmetros monitorados, comparando-os com os limites estabelecidos pela classe de enquadramento e indicando se os valores estão ou não em conformidade com os limites. Se a estação apresentar pelo menos um parâmetro que não esteja em conformidade com os limites da classe de enquadramento, esta estação é indicada como uma estação que não está em conformidade com a classe. Nesta operação de validação, são considerados somente os parâmetros para os quais houve leitura na campanha (ou nas campanhas) em questão. Mesmo que se tenha cadastrado para a classe de enquadramento toda uma série de parâmetros com seus respectivos limites, somente tem efeito para a validação do enquadramento aqueles parâmetros que realmente foram monitorados pelo programa com o qual se está trabalhando. 
O módulo de apoio ao enquadramento inclui também um gráfico que permite visualizar as leituras realizadas comparando-as com os limites estabelecidos por uma determinada classe de enquadramento. Assim, é possível identificar visualmente quais as leituras que não estão em conformidade com os padrões de qualidade (limites máximos ou mínimos) da classe. Um exemplo deste gráfico está na Figura 4.

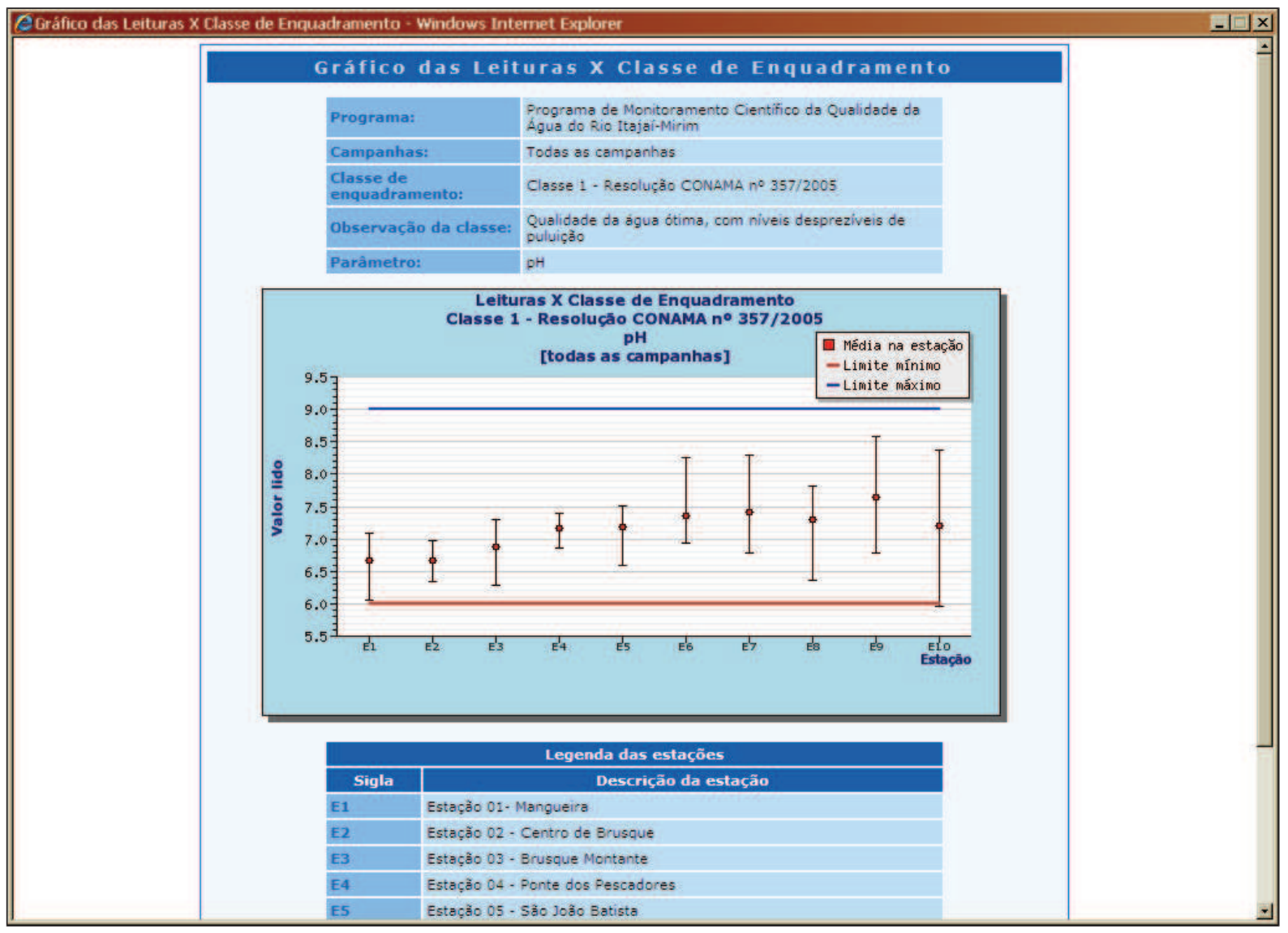

Figura 4 - Gráfico das Leituras X Classe de Enquadramento

\section{Considerações finais}

Depois de concluída a implementação do SI, foram realizados testes utilizando dados reais, resultantes de campanhas de coleta realizadas pela equipe do Laboratório de Estudos de Impactos Ambientais (LEIA), da UNIVALI. A inserção destes dados no SI, além de permitir a produção de alguns resultados como gráficos e relatórios, para efeito de validação destes recursos, permitiu também avaliar o modelo de SI proposto frente a uma situação real.

Dentre as funções implementadas, se destacam o armazenamento de dados de programas de monitoramento, a análise destes dados através da construção de gráficos e relatórios e o apoio ao enquadramento através da comparação entre os dados de qualidade armazenados na base de dados com os limites estabelecidos para cada classe de enquadramento. Complementarmente, as classes de enquadramento e os valores limites para cada um dos parâmetros de qualidade podem ser cadastrados de acordo com a necessidade de cada usuário. Assim, sempre que houver qualquer alteração na legislação que estabelece estes limites, o sistema pode ser ajustado pelo próprio usuário. 
Os testes realizados demonstraram que o módulo de suporte ao monitoramento da qualidade da água é adequado para aplicação em diferentes programas de monitoramento, que podem apresentar características distintas. Esta característica foi destacada como uma das características desejáveis para um SI sobre recursos hídricos no levantamento realizado em Silva (2007). O fato do módulo de monitoramento da qualidade da água ser customizável pode ser considerado um dos diferenciais do modelo proposto neste trabalho, pois os SI estudados por Silva (2007) não apresentam tal característica, tendo sido desenvolvidos para aplicação em situações específicas. $O$ emprego destes sistemas em programas de monitoramento que apresentem características diferentes daquele para o qual o sistema foi originalmente modelado pode ser dificultado e até mesmo, inviabilizado.

A flexibilidade oferecida pelo SI proposto pode ser útil, também, em situações de alteração nos parâmetros monitorados por um programa de monitoramento (acréscimo de um novo parâmetro ou exclusão de um que já era monitorado), a fim de atender a determinadas normas ou mesmo, por solicitação dos interessados nos dados do referido programa.

$\mathrm{O}$ armazenamento sistematizado dos dados de qualidade, aliado às funcionalidades de geração de gráficos e relatórios com base nestes dados, oferecem diferentes visões da evolução da qualidade da água sob diferentes perspectivas, proporcionadas por diferentes combinações destas funcionalidades, de acordo com o conhecimento que se deseja extrair dos dados. Para complementar este conhecimento, dados de vazão podem ser cadastrados ou importados para a base de dados do SI, permitindo a análise comparativa da evolução da vazão do corpo hídrico e da evolução da qualidade da água. Assim, é possível identificar eventuais relações entre a vazão de um corpo d'água e as condições de qualidade apresentadas por ele.

As funcionalidades neste módulo foram avaliadas positivamente pela equipe do LEIA, que pode ser considerado um potencial usuário de uma versão completa e operacional do SI proposto e a importância da flexibilidade na definição dos parâmetros monitorados em cada programa de monitoramento foi confirmada, tendo em vista que este laboratório realiza o monitoramento da qualidade da água em diferentes localidades, com diferentes objetivos e, consequentemente, os parâmetros monitorados em cada programa podem variar.

O código fonte do SI está sendo disponibilizado livremente no repositório GitHub, com o objetivo de que outras instituições tenham acesso ao mesmo, bem como, colaborem na manutenção e ampliação do projeto.

\section{Referencias bibliográficas}

ANA - Agência Nacional de Águas. Rede de Monitoramento de Qualidade de Águas. em: [http://www.ana.gov.br/gestaoRecHidricos/InfoHidrologicas/projetos_redeMonitQualid 2.asp] Consultado em: 18 de junho de 2004.

BORSOI, Z. M. F.; TORRES, S. D. A. A política de recursos hídricos no Brasil. Revista do BNDES, Rio de Janeiro, v. 4, n. 8, dez. 1997, p. 143-166.

COPPETEC Fundação. Sistema de Informações de Recursos Hídricos para a Bacia do Paraíba do Sul: Manual do Usuário. Rio de Janeiro: UFRJ, 2002. 
IGAM - Instituto Mineiro de Gestão das Águas. Enquadramento. Disponível em: [http://www.igam.mg.gov.br]. Consultado em: 20 de fevereiro de 2007.

LAUDON, Keneth C.; LAUDON, Jane Price. Sistemas de Informação com Internet. Rio de Janeiro: LTC Editora, 1999. 4ed. Traduzido por: Dalton Conde de Alencar.

PORTO, M. Integrating Water Management: Quantity and Quality. In: POLICY AND INSTITUTIONS FOR INTEGRATED WATER RESOURCES MANAGEMENT IWRM, São Paulo, 2000. Proceedings. São Paulo: International Water Resources Association, 2000.

SILVA, R. R. Protótipo de sistema de informação para monitoramento de qualidade da água e apoio ao enquadramento de corpos hídricos baseado em tecnologias open source. 2007. 85f. Dissertação (Mestrado em Ciência e Tecnologia Ambiental) - Centro de Ciências Tecnológicas da Terra e do Mar, UNIVALI, Itajaí SC.

SPERB et al. SAGREH: Um Sistema de Apoio à Gestão de Recursos Hídricos com Suporte Espacial Baseado em Tecnologia Open Source e Internet. In: GIS BRASIL 2004 - $10^{\circ}$ Show Internacional de Geotecnologias, 2004. Anais... São Paulo: GIS BRASIL, 2004.

TUCCI, Carlos. E. M.; HESPANHOL, Ivanildo.; CORDEIRO NETTO, Oscar de M. Relatório Nacional sobre o Gerenciamento da Água no Brasil. Rio Grande do Sul: Instituto de Pesquisas Hidráulicas - Universidade Federal do Rio Grande do Sul, 2000. 